\title{
Exploring the role of obesity and overweight in predicting postoperative outcome of abdominal surgery in a sub-Saharan African setting: a prospective cohort study
}

\author{
Benjamin Momo Kadia ${ }^{12^{*}} \mathbb{0}$, Alain Chichom-Mefire ${ }^{3}$ and Gregory Edie Halle-Ekane ${ }^{3}$
}

\begin{abstract}
Objective: Current literature on the role of excess weight in predicting surgical outcome is controversial. In subSaharan Africa, there is extreme paucity of data regarding this issue in spite of the increasing rates of obesity and overweight in the region. This prospective cohort study, carried out over a period of 4 months at Limbe Regional Hospital in the Southwest region of Cameroon, assessed 30-day postoperative outcome of abdominal surgery among consecutive adults with body mass index $(\mathrm{BMI}) \geq 25 \mathrm{~kg} / \mathrm{m}^{2}$. Adverse postoperative events were reported as per Clavien-Dindo classification.

Results: A total of 103 patients were enrolled. Of these, $68.9 \%$ were female. The mean age was $38.2 \pm 13.7$ years. Sixty-four (62.1\%) of the patients were overweight and the mean BMI was $29.2 \pm 4.3 \mathrm{~kg} / \mathrm{m}^{2}$. The physical status scores of the patients were either I or II. Appendectomy, myomectomy and hernia repair were the most performed procedures. The overall complication rate was 13/103 (12.6\%), with 61.5\% being Clavien-Dindo grades II or higher. From the lowest to the highest BMI category, there was a significant increase in the proportion of patients with complications; $25-29.9 \mathrm{~kg} / \mathrm{m}^{2}: 6.25 \%, 30-34.9 \mathrm{~kg} / \mathrm{m}^{2}: 18.75 \%, 35-39.9 \mathrm{~kg} / \mathrm{m}^{2}: 25.0 \%$, and $\geq 40 \mathrm{~kg} / \mathrm{m}^{2}: 66.70 \% ; p=0.0086$.
\end{abstract}

Keywords: BMI, Obesity, Overweight, Postoperative outcome, Abdominal surgery, Sub-Saharan Africa

\section{Introduction}

Obesity and overweight are a global public health problem [1-3]. A rapid rise in the prevalence of obesity and overweight has been observed in both developed and developing countries $[1,3,4]$. Although a lower prevalence is generally reported in African countries, the trend has been towards a rapid rise in the number of obese and overweight people [2]. In Cameroon, the prevalence of obesity in urban areas has been estimated to range between 5.4 to $6.5 \%$ in males and 17.1 to $19.5 \%$ in females and the trend is also on the rise $[5,6]$.

\footnotetext{
*Correspondence: benjaminmomokadia@gmail.com

2 Faculty of Infectious and Tropical Diseases, London School of Hygiene and Tropical Medicine, London, UK

Full list of author information is available at the end of the article
}

From a surgical perspective, the increasing rate of obesity and overweight has been associated with a rise in the number of persons with excess weight who need to undergo surgery $[3,7,8]$. In Western countries, studies have indicated that excess weight is an independent predictor of adverse surgical outcome, with morbid obesity being associated with a higher risk of postoperative death [9-13]. This association is confirmed by some of the rare available reports in Africa [8, 14-17]. With the introduction of laparoscopic surgery, surgical interventions appear to have become much safer in persons with excess weight [18-20]. Notwithstanding the above mentioned, some authors have reported contrary findings on the role of obesity and overweight in predicting surgical morbidity and mortality. Consequently, literature on the 
association between obesity and overweight and surgical outcome has remained controversial [7, 21-24].

In Cameroon, there has been a gradual improvement in surgical infrastructure especially with the introduction of laparoscopic surgery which is, however, unavailable at regional and district levels of healthcare where over $70 \%$ of the population is treated [25]. This setting, where mainly open abdominal surgery is performed, is characterized by extreme paucity of data on postoperative outcome among obese and overweight persons. This study sought to grade adverse postoperative outcome of open abdominal surgery among obese and overweight persons and to assess the variation of postoperative complication rates across body mass index (BMI) strata for obese and overweight persons at a regional hospital in the Southwest region of Cameroon. We hypothesized that obesity and overweight is associated with high complication rates.

\section{Main text}

\section{Materials and methods}

\section{Study design and setting}

A prospective cohort study was carried out over a 4-month period (November 01st, 2014 to February 28th, 2015) at the surgical and gynaecological wards of Limbe Regional Hospital (LRH). LRH is based in the Southwest region of Cameroon and is a level III referral centre. During the study, the surgical ward had 24 beds and was run by a general surgeon while the obstetrics/gynaecology ward had 24 beds and was managed by 2 obstetricians/ gynaecologists. At the time of the study, LRH has 2 functional operative rooms and there was no intensive care unit. Serious cases were referred to Douala where there are larger hospitals with specialized services.

\section{Patients}

The study population was enrolled by consecutive convenience sampling. We selected overweight and obese patients $\left(\mathrm{BMI} \geq 25 \mathrm{~kg} / \mathrm{m}^{2}\right)$ aged $\geq 18$ years undergoing abdominal surgery, defined arbitrarily as any procedure involving incision and opening of the layers of the abdomen and/or its surroundings for diagnostic or therapeutic purposes, irrespective of whether the peritoneum was opened or not. Repeat surgeries were excluded as well as patients from whom sufficient relevant data could not be obtained.

\section{Data sources and measurements}

Overweight and obesity was the main exposure variable and was defined by $\mathrm{BMI} \geq 25 \mathrm{~kg} / \mathrm{m}^{2}$. Preoperative BMI was calculated as weight (in kilograms) divided by height (in metres) squared and patients were stratified by BMI into groups defined by the World Health Organization (WHO), with overweight being BMI $\geq 25 \mathrm{~kg} / \mathrm{m}^{2}$ to $<30 \mathrm{~kg} / \mathrm{m}^{2}$ and obesity being BMI $>30 \mathrm{~kg} / \mathrm{m}^{2}$. For elective procedures, weight and height were measured $24 \mathrm{~h}$ prior to surgery by the principal investigator (a medical doctor). For patients requiring emergency surgery, BMI was computed from the most recent (at most 3 weeks prior to surgery) weights and heights in their medical records. Other explanatory variables such as demographics, preoperative diagnoses as reported by the attending surgeon or gynaecologist, and American Society of Anaesthesiology (ASA) physical status scores were recorded. ASA scores include: ASA 1: A normal healthy patient; ASA 2: A patient with a mild systemic disease such as treated hypertension or diabetes; ASA 3: A patient with a severe systemic disease that is not life-threatening like poorly treated hypertension or diabetes; ASA 4: A patient with a severe systemic disease that is a constant threat to life such as unstable angina, and recent myocardial infarction or stroke; ASA 5: A moribund patient who is not expected to survive without the operation.

Patients were also followed-up in the operating room where data such as type of anaesthesia, type of procedure and the risk of sepsis (as per the 1999 Centers for Disease Control and Prevention guidelines of prevention of surgical site infection [26]), were recorded. Variables such as age, status of surgery (major versus minor), anaemia (defined as per WHO standards as haemoglobin level of $<13 \mathrm{~g} / \mathrm{dl}$ in men and $<12 \mathrm{~g} / \mathrm{dl}$ in women) and type of surgery (elective versus emergency) and surgical wound class whose subcategories could have differential postoperative outcome were considered as potential effect modifiers. Potential confounding variables such as physical status score, and duration of surgery were also noted. The primary outcome was 30-day complications as defined by the Clavien-Dindo classification which is a widely used scoring system for adverse surgical events [3, 27-29]. Based on this classification, there are 5 grades of complications:

- Grade I: no pharmacological, surgical, endoscopic or radiological interventions are required. Allowed therapeutic regimens are drugs such as antiemetics, antipyretics, analgesics, diuretics, electrolytes and physiotherapy. This grade also includes wound infections opened at the bedside.

- Grade II: pharmacological treatment with drugs other than those allowed for grade I complications is required. Blood transfusion and total parenteral nutrition are also included here.

- Grade III: require surgical, endoscopic or radiological intervention. 
- Grade IV: life-threatening (including central venous system complications) and requires intensive care.

- Grade V: death of the patient [27].

Complications were diagnosed and reported in patients' medical records by the attending surgeon and gynaecologist. Secondary outcomes included readmissions, reoperations, and referrals.

\section{Data analysis}

All data were entered in an MS excel spread sheet and analyzed using Epi-Info version 7 statistical software. Categorical (binary) variables were compared using the Chi square or Fisher's exact test as appropriate. Bivariate analysis enabled the determination of other factors (confounders and effect modifiers) that were potentially associated with postoperative complications in our cohort. Means and proportions were compared using Student's two-sample t-tests (when comparing two groups) or ANOVA tests (when comparing more than 2 groups). The threshold for statistical significance was set at $\mathrm{p}<0.05$.

\section{Results}

\section{Inclusion rate}

One hundred and twenty-three persons were potentially eligible for this study. They were all examined for eligibility. There were 116 patients who were confirmed eligible for the study but 13 were excluded because their data were incomplete. Thus, the inclusion rate was $88.8 \%$.

\section{Demographic and preoperative characteristics}

A total of 103 patients were finally enrolled. There were 32 males, giving a male to female ratio of 0.43 . The age range was 18 to 83 years with a mean of $38.2 \pm 13.7$ years. BMI ranged from 25.0 to $52.1 \mathrm{~kg} / \mathrm{m}^{2}$, with a mean of 29.2 \pm 4.3 . As shown in Fig. 1, 64 (62.1\%) of the patients were overweight and among the 39 obese patients, $7.7 \%$ were morbidly obese. Physical status scores were either I or II. Preoperative anaemia was observed in $40(38.8 \%)$ of the patients (Table 1 ).

\section{Operative characteristics}

A total of $51(49.5 \%)$ of surgical procedures were performed as emergencies and $59(57.9 \%)$ were major procedures (Table 1). Major procedures included myomectomy and laparotomy for ectopic pregnancy. Minor procedure included hernia repair and appendectomy. The most frequently performed surgical procedures were appendectomy, hernia repair and myomectomy. Of the 103 patients, $73.79 \%$ were operated on under general anaesthesia and $16.5 \%$ patients required perioperative blood transfusion.

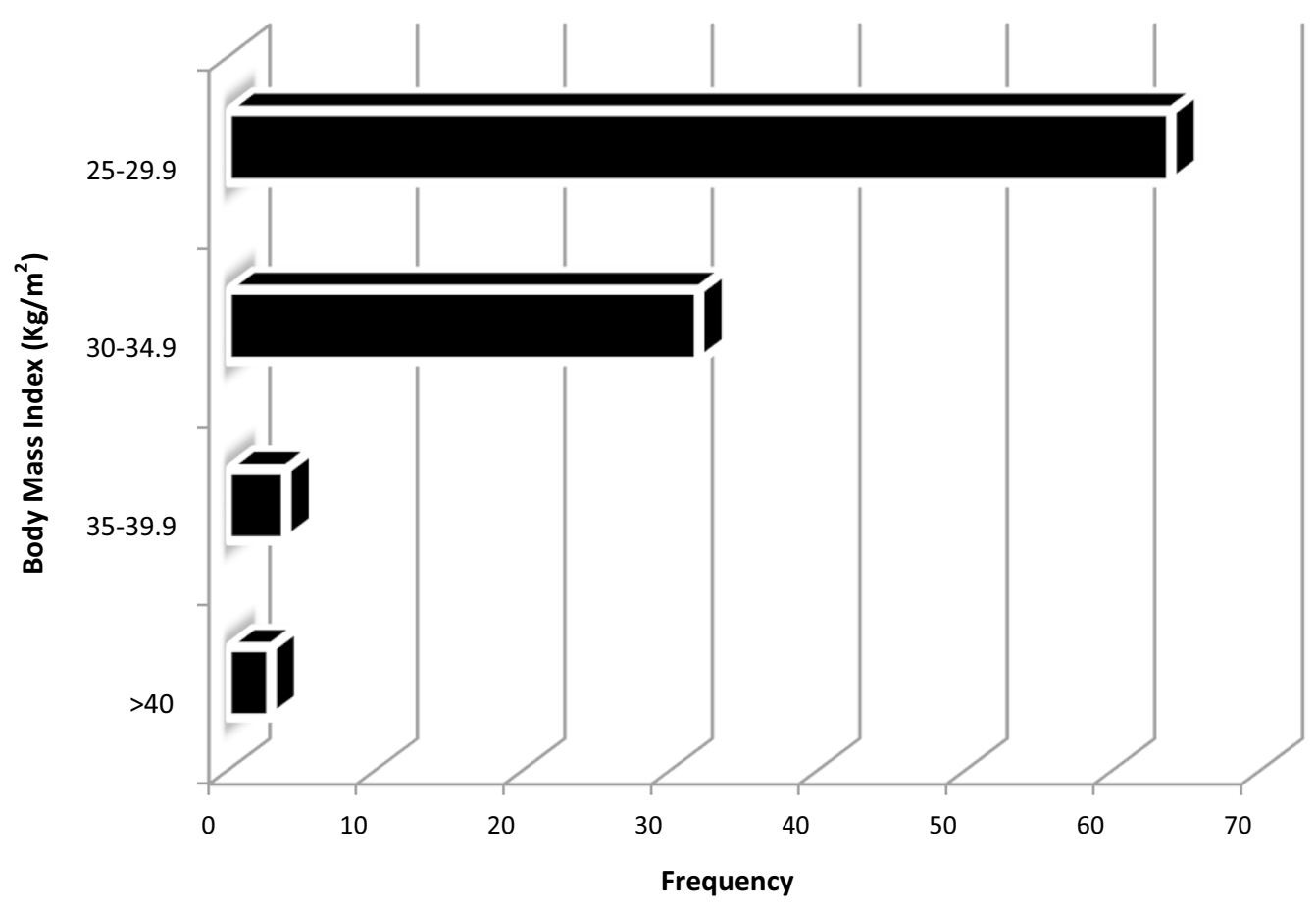

Fig. 1 BMl stratification of study population 
Table 1 Preoperative and operative characteristics of study population

\begin{tabular}{lc}
\hline Variable & $\mathbf{n = 1 0 3 ( \% )}$ \\
\hline Preoperative anaemia & \\
No & $63(61.2 \%)$ \\
Yes & $40(38.8 \%)$ \\
Status of surgical procedure & \\
Elective & $52(50.5 \%)$ \\
Emergency & $51(49.5 \%)$ \\
Type of surgical procedure & \\
Major & $59(57.3 \%)$ \\
Minor & $44(43.7 \%)$ \\
Type of anaesthesia & \\
General & $77(74.8 \%)$ \\
Locoregional & $16(15.5 \%)$ \\
Regional & $10(9.7 \%)$ \\
Estimated blood loss (ml) & \\
$<1000$ & $94(91.3 \%)$ \\
$>1000$ & $9(8.7 \%)$ \\
Surgical wound class & \\
Non septic & $70(68 \%)$ \\
Septic & $33(32 \%)$ \\
Perioperative transfusion & \\
No & \\
Yes & $86(83.5 \%)$ \\
Duration of surgical procedure (h) & $17(16.5 \%)$ \\
$\leq 2$ & \\
\hline 2 & $21(20.4 \%)$ \\
\hline
\end{tabular}

\section{Postoperative outcome}

A total of 13 complications were recorded $(12.6 \%$ complication rate). Majority of complications (93.9\%) were Clavien-Dindo grades 1 and 2 (minor complications) and the rest $(6.1 \%)$ were grade 3 or higher (major complications). No cases of readmissions, reoperations, deaths or referrals were registered. Differential analysis of complication rates indicated that from the lowest to the highest BMI strata, there was a significant increase in proportion of patients who developed postoperative complications (Table 2). Bivariate analysis of potential confounders and effect modifiers including gender (male versus female), age ( $>38$ years or $\leq 38$ years), comorbidities like diabetes and hypertension, duration of procedure ( $\leq 2 \mathrm{~h}$ or $>2 \mathrm{~h}$ ), surgical wound class (non-septic versus septic), status of procedure (major versus minor), preoperative anaemia, estimated blood loss $(<1000 \mathrm{ml}$ or $\geq 1000 \mathrm{ml})$ and type of anaesthesia (general versus regional), was remarkable in that the occurrence of complications was significantly higher among patients of age $>38$ years compared to patients of age $\leq 38$ years $(21 \%$ versus $5.4 \%, \mathrm{p}=0.016)$.
Table 2 Variation of complication rates across BMI strata

\begin{tabular}{lllll}
\hline $\begin{array}{l}\text { BMI (kg/ } \\
\left.\mathbf{m}^{\mathbf{2}}\right)\end{array}$ & Complications & $\begin{array}{l}\text { No } \\
\text { complication }\end{array}$ & $\begin{array}{l}\text { Complication } \\
\text { rate }(\%)\end{array}$ & p value \\
\hline $\begin{array}{c}25-29.9 \\
(n=64)\end{array}$ & 4 & 60 & 6.25 & 0.0086 \\
$\begin{array}{c}30-34.9 \\
(n=32)\end{array}$ & 6 & 26 & 18.75 & \\
$\begin{array}{c}35-39.9 \\
(n=4)\end{array}$ & 1 & 3 & 25 & \\
$\geq 40$ & 2 & 1 & 66.7 & \\
$(n=3)$ & & & 12.62 & \\
\hline \begin{tabular}{l} 
Total (103) \\
\hline
\end{tabular} & 13 & 90 & & \\
\hline
\end{tabular}

\section{Discussion}

This prospective study intended to grade postoperative complications of abdominal surgery among overweight and obese persons and to determine if there is an association between BMI strata and complications. Based on the results of the study, obese and overweight patients undergoing abdominal surgery had good Physical status scores and anaemia was a frequent associated condition. The overall complication rate was rather high and the relative risk seemed to increase with BMI. Furthermore, when complications occurred, they tended to be of low severity.

African countries are characterized by an alarming lack of reports on the epidemiology and morbidity of obesity and overweight and its possible bearing on the management of surgical patients. This study is one of the rare focusing on the outcome of abdominal surgery in obese and overweight patients in sub-Saharan Africa. To the best of our knowledge, it is the first documented Cameroonian study primarily designed to investigate whether obesity and overweight is associated with higher risk of postoperative complications. It has the merits of comparing postoperative outcome across BMI strata and the prospective nature of the study as well as the use of a validated method of reporting surgical outcome increase the level of evidence proposed and external validity of the results. Our findings contribute to addressing current controversies on the impact of obesity on surgical outcomes and attempt to contribute to solving the crucial problem of the alarming lack of data and guidelines for surgeons practicing in subSaharan African countries.

The mean BMI in our cohort was low in comparison to many studies assessing postoperative outcome among patients with excess weight because these studies assessed obese patients as a single group [13, 24, $30-32]$. It is frequently reported that obese patients undergoing surgery have a high prevalence of comorbidities such as diabetes, hypertension and sleep apnea 
which can adversely affect surgical outcome [24]. Our patients were generally overweight which is associated with a lower risk of comorbidities. A low rate of comorbidities could explain the overall good physical status score and the low severity of complications observed. According to current literature, the relation between excess weight and surgical outcome is controversial. Obesity has long been pointed as an independent risk factor of postoperative morbidity and mortality $[9,11$, $13,24,30,31,33-35]$. The relative risk is described as BMI dependent $[9,13,15,36,37]$ as observed in our study. Specific complications have been identified at all the steps of the surgical management process. In the pre-operative phase, they seem to be mostly related to the respiratory problems often displayed by obese patients which sometimes result in the need to initiate or prolong the stay in the Intensive Unit with ventilator support [13, 24, 31, 38]. Intra-operatively, morbidity is dominated by bleeding and a longer operative time probably due to operative ergonomics and poorer exposure of the surgical site [33, 39]. Post-operative morbidity is dominated by the risk of local sepsis and abdominal wall defect $[24,30,34,35,40]$. Other complications which seem to be frequent in obesity such as myocardial infarction and multi-organ failure did not appear in our report, probably because they are more frequent in morbidly obese patients [7, 13, 34].

Obesity-related risks appear to have significantly reduced with the introduction of laparoscopy, especially for procedures popularly known as providers of postoperative complications in the obese [18-20, 4144]. Nonetheless, the association between obesity and adverse surgical outcome may not be clear-cut as contradictory reports are available [7, 32, 40, 45]. It is often suspected that the numerous previous reports pointing obesity as a risk factor of adverse surgical outcome may have inspired the over-reporting of postoperative complications in obese patients [46]. We limited such bias by reporting complications using a validated (standard) scoring system. Furthermore, obesity and overweight were estimated using a standard method (BMI) and the estimates were done by medical doctors. These reduced the chances of measurement bias regarding the predictor variable of interest (BMI). However, the magnitude of the relative risk of complications across BMI strata may have been increased by confounders and effect modifiers and this may have led to bias away from the null hypothesis.

In conclusion, the findings of this study suggest that among adults with excess weight, increased BMI seems to be associated with adverse postoperative outcome of abdominal surgery. Special preparation and monitoring may therefore be justified for obese and overweight patients in our setting. Obese and morbidly obese persons undergoing abdominal surgical procedures seem to require more caution and consequently, appropriate measures such as prolonged assisted ventilation and aggressive infection prevention plans should be considered when handling the postoperative period.

\section{Limitations}

The global lack of consistency in the definition of obesity and in particular the paucity of data on obesityrelated surgical morbidity in developing countries limited the interpretation of our findings. Furthermore, this study used BMI as measure of adiposity albeit it is suggested that the percentage of fat contributing to total body weight and the body distribution of fat are key in understanding health risks (including surgical outcome) associated with excess weight $[7,30]$. Although the small sample size as well as lack of a control group and sensitivity analysis limit the external validity of the results, standard methods were used to measure adiposity and report complications which increase the validity of our findings. A larger prospective study possibly including control groups and comparative analyses of different measures of adiposity as predictors of surgical outcome could have better defined the effect of excess weight on postoperative outcome.

\section{Abbreviations}

ASA: American Society of Anaesthesiologists; BMI: body mass index; WHO: World Health Organization.

\section{Authors' contributions}

BMK: conception of the study, literature review, data acquisition and preparation of the manuscript. ACM: conception of the study, data interpretation and review of the manuscript for technical and intellectual consistencies. GEHE: interpretation of data, review of manuscript and provision of technical guidance. All authors read and approved the final manuscript.

\section{Author details}

${ }^{1}$ Grace Community Health and Development Association, Kumba, Southwest Region, Cameroon. ${ }^{2}$ Faculty of Infectious and Tropical Diseases, London School of Hygiene and Tropical Medicine, London, UK. ${ }^{3}$ Faculty of Health Sciences, University of Buea, Buea, Southwest Region, Cameroon.

\section{Acknowledgements}

To all the patients who kindly accepted to participate in this study.

\section{Competing interests}

The authors declare that they have no competing interests.

\section{Availability of data and materials}

The data generated in this article will be made available on request by the corresponding author.

\section{Consent for publication}

Not applicable.

\section{Ethics approval and consent to participate}

Ethical registry was obtained from the Institutional Review Board of the University of Buea prior to the beginning of the study under No. 2014-10-0341. Administrative authorization was obtained from the Southwest regional delegation of public health and from the administration of $\mathrm{LRH}$. After accepting to 
participate to the study, each patient included signed an individual informed consent form.

\section{Funding}

This research received no funding support.

\section{Publisher's Note}

Springer Nature remains neutral with regard to jurisdictional claims in published maps and institutional affiliations.

Received: 4 September 2018 Accepted: 12 October 2018

Published online: 19 October 2018

\section{References}

1. Kelly T, Yang W, Chen CS, Reynolds K, He J. Global burden of obesity in 2005 and projections to 2030. Int J Obes (Lond). 2008:32(9):1431-7.

2. Yatsuya H, Li Y, Hilawe EH, Ota A, Wang C, Chang C, et al. Global trend in overweight and obesity and its association with cardiovascular disease incidence. Circ J. 2014;78(12):2807-18.

3. Nepogodiev D, Chapman SJ, Glasbey J, Kelly M, Khatri C, Drake TM, et al. Determining Surgical Complications in the Overweight (DISCOVER): a multicentre observational cohort study to evaluate the role of obesity as a risk factor for postoperative complications in general surgery. BMJ Open. 2015;5:e008811. https://doi.org/10.1136/bmjopen-2015-008811.

4. Haslam D, James P. Obesity. Lancet. 2005;366(1197-120):9.

5. Sobngwi E, Mbanya J-CN, Unwin NC, Kengne AP, Fezeu L, Minkoulou EM, et al. Physical activity and its relationship with obesity, hypertension and diabetes in urban and rural Cameroon. Int J Obes Relat Metab Disord. 2002;26:1009-16.

6. Kamadjeu RM, Edwards R, Atanga JS, Kiawi EC, Unwin N, Mbanya J. Anthropometry measures and prevalence of obesity in the urban adult population of Cameroon: an update from the Cameroon Burden of Diabetes Baseline Survey. BMC Public Health. 2006;6:228.

7. Doyle SL, Lysaght J, Reynolds JV. Diagnostic in obesity and complications: obesity and postoperative complications in patients undergoing nonbariatric surgery. Obes Rev. 2009;11:875-86.

8. Zoumenou E, Mensah E, Dossou F, Kaboro M, Kerekou A, Tchaou B, et al. Prevalence and complications of obesity in surgical patients: a multicenter study in Benin, a sub-Saharan African Country. Epidemiol. 2012;2:2-4.

9. Al-Mulhim AS, Al-Hussaini HA, Al-Jalal BA, Al-Moagal RO, Al-Najjar SA. Obesity disease and surgery. Int J Chronic Dis. 2014;2014:652341. https:// doi.org/10.1155/2014/652341.

10. Utsunomiya T, Okamoto M, Kameyama T, Matsuyama A, Yamamoto M. Impact of obesity on the surgical outcome following repeat hepatic resection in Japanese patients with recurrent hepatocellular carcinoma. World J Gastroenterol. 2008;14:1553-8.

11. Klos CL, Safar B, Jamal N, Hunt SR, Wise PE, Birnbaum EH, et al. Obesity increases risk for pouch related complications following restorative proctocolectomy with lleal pouch — anal anastomosis. J Gastrointest Surg. 2013:18:573-9.

12. Balentine C, Enriquez J, Cruz G, Hodges S, Bansal V, Jo E, et al. Obesity does not increase complications following pancreatic surgery. J Surg Res. 2011;170:220-5.

13. Bamgbade OA, Rutter TW, Nafiu OO, Dorje P. Postoperative complications in obese and non-obese patients. World J Surg. 2007;31:556-60.

14. Nwankwo O, Ibeh N, Enabulele I. Incidence and risk factors of surgical site infection in a tertiary health institution in Kano, Northwestern Nigeria. Int $\mathrm{J}$ Infect Control. 2012;8:8-13.

15. Ibrahim WA, Mohamed AA. Obesity deleteriously affects anaesthetic and surgical outcome in body mass index-dependent fashion, Egypt. J Anaesth. 2013:29:195-201.

16. Edomwonyi N, Osaigbovo P. Incidence of Obesity in parturients scheduled for caesarean section, intraoperative complications, management and outcome. East Afr Med J. 2006;83:112-9.

17. Ntsama E, Avomo J, Esiene A, Leme B, Abologo A, Masso M, et al. Prevalence of surgical site infections and evaluation of risk factors after surgery, case of three public hospitals in Cameroon. J Med Med Sci. 2011;4:241-6.
18. Bige Ö, Demir A, Saatli B, Koyuncuoğlu M, Saygılı U. Laparoscopy versus laparotomy for the management of endometrial carcinoma in morbidly obese patients: a prospective study. J Turk Ger Gynecol Assoc. 2015;16(3):164-9.

19. Schwandner O, Farke S, SchiedeckTH, Bruch HP. Laparoscopic colorectal surgery in obese and non-obese patients: do differences in body mass indices lead to different outcomes? Surg Endosc. 2004;18(10):1452-6.

20. Paajanen $H$, Käkelä P, Suuronen S, Paajanen J, Juvonen P, Pihlajamäki J. Impact of obesity and associated diseases on outcome after laparoscopic cholecystectomy. Surg Laparosc Endosc Percutan Tech. 2012;22(6):509-13.

21. Balentine C, Robinson C, Marshall C, Wilks J, Buitrago W, Haderxhanaj $\mathrm{K}$, et al. Waist circumference predicts increased complications in recta cancer surgery. J Gastrointest Surg. 2010;14:1669-79.

22. Harmanli O, Dandolu V, Lidicker J, Ayaz R, Panganamamula U, Iskik E. The effect of obesity on total abdominal hysterectomy. J Women's Health. 2010;10:1915-8.

23. Mullen J, Davenport D, Hutter M, Hosokawa P, Henderson W, Khuri S, et al. Impact of body mass index on perioperative outcomes in patients undergoing major intra-abdominal cancer surgery. Ann Surg Oncol. 2008;15:2164-72

24. Ferrada P, Anand RJ, Malhotra A, Aboutanos M. Obesity does not increase mortality after emergency surgery. J Obes. 2012;2014:492127.

25. Raiga J, Kasia JM, Bruhat MA. Laparoscopic surgery in the Cameroon. Int J Gynaecol Obstet. 1999;65(1):65-6.

26. Mangram AJ, Horan TC, Pearson ML, Silver LC, Jarvis WR. Guideline for prevention of surgical site infection, 1999. Centers for Disease Control and Prevention (CDC) Hospital Infection Control Practices Advisory Committee. Am J Infect Control. 1999;27(2):97-132 (quiz 133-4; discussion 96).

27. Clavien PA, Barkun J, de Oliveira ML, Vauthey JN, Dindo D, Schulick RD, et al. The Clavien-Dindo classification of surgical complications: five-year experience. Ann Surg. 2009;250:187-96.

28. Kadia BM, Aroke D, Abanda MH, Njim T, Dimala CA. Bowel resection and ileotransverse anastomosis as preferred therapy for 15 typhoid ileal perforations and severe peritoneal contamination in a very elderly patient. Case Rep Surg. 2017. https://doi.org/10.1155/2017/9424237.

29. Kamarajah SK, Sowida M, Adlan A, Barmayehvar B, Reihill C, Ellahee P. Preoperative assessment of patients undergoing elective gastrointestinal surgery: does body mass index matter? J Obes. 2017;1:1. https://doi. org/10.1155/2017/4285204.

30. Waisbren E, Rosen H, Bader AM, Lipsitz SR, Rogers SO Jr, Eriksson E. Percent body fat and prediction of surgical site infection. J Am Coll Surg. 2010;210(4):381-9.

31. Küpper S, Karvellas CJ, Khadaroo RG, Widder SL, Acute Care and Emergency Surgery (ACES) Group. Increased health services use by severely obese patients undergoing emergency surgery: a retrospective cohort study. Can J Surg. 2015;58(1):41-7

32. Herrera FA, Yanagawa J, Johnson A, Limmer K, Jackson N, Savu MK. The prevalence of obesity and postoperative complications in a Veterans Affairs Medical Center general surgery population. Am Surg. 2007;73(10):1009-12

33. Osler M, Daugbjerg S, Frederiksen BL, Ottesen B. Body mass and risk of complications after hysterectomy on benign indications. Hum Reprod. 2011;26(6):1512-8.

34. Duchesne JC, Schmieg RE Jr, Simmons JD, Islam T, McGinness CL, McSwain NE Jr. Impact of obesity in damage control laparotomy patients. J Trauma. 2009;67(1):108-12 (discussion 112-4).

35. Anaya DA, Dellinger EP. The obese surgical patient: a susceptible host for infection. Surg Infect (Larchmt). 2006;7(5):473-80.

36. Karvellas C, Suzana K, Khadaroo R, Widder S. Increased health services use by severely obese patients undergoing emergency surgery: a retrospective cohort study. Can J Surg. 2014;58:41-7.

37. Williams TK, Rosato EL, Kennedy EP, Chojnacki KA, Andrel J. Impact of obesity on perioperative morbidity and mortality following pancreaticoduodenectomy. J Am Coll Surg. 2009;208:210-7.

38. Pelosi P, Gregoretti C. Perioperative management of obese patients. Best Pract Res Clin Anaesthesiol. 2010:24(2):211-25.

39. Tjeertes EK, Hoeks SE, Beks SB, Valentijn TM, Hoofwijk AG, Stolker RJ. Obesity-a risk factor for postoperative complications in general surgery? BMC Anesthesiol. 2015;31(15):112. https://doi.org/10.1186/s12871-015-0096-7. 
40. Dindo D, Muller MK, Weber M, Clavien PA. Obesity in general elective surgery. Lancet. 2003;361:2032-5.

41. Estay C, Zarate AJ, Castro M, Kronberg U, López-Köstner F, Wainstein C Does obesity increase early postoperative complications after laparoscopic colorectal surgery? Results from a single center. Surg Endosc. 2014;28(7):2090-6.

42. Michailidou M, Sacco Casamassima MG, Goldstein SD, Gause C, Karim O, Salazar JH, et al. The impact of obesity on laparoscopic appendectomy: results from the ACS National Surgical Quality Improvement Program pediatric database. J Pediatr Surg. 2015;50(11):1880-4.

43. Mason RJ, Moazzez A, Moroney JR, Katkhouda N. Laparoscopic vs open appendectomy in obese patients: outcomes using the American College of Surgeons National Surgical Quality Improvement Program database. J Am Coll Surg. 2012;215(1):88-99 (discussion 99-100).

44. Keller DS, Madhoun N, Flores-Gonzalez JR, Ibarra S, Tahilramani R, Haas EM. Effect of BMI on short-term outcomes with robotic-assisted laparoscopic surgery: a case-matched study. J Gastrointest Surg. 2016;20(3):488-93.

45. Livingston DH, Lavery RF, Nkanza A, Anjaria D, Sifri ZC, Mohr AM, et al. Obesity does not increase morbidity and mortality after laparotomy for trauma. Am Surg. 2013;79(3):247-52.

46. Garrow JS, Hastings EJ, Cox AG, North WRS, Gibson M, Thomas TM, et al. Obesity and postoperative complications of abdominal operation. $\mathrm{Br}$ Med J. 1988;297:18
Ready to submit your research? Choose BMC and benefit from:

- fast, convenient online submission

- thorough peer review by experienced researchers in your field

- rapid publication on acceptance

- support for research data, including large and complex data types

- gold Open Access which fosters wider collaboration and increased citations

- maximum visibility for your research: over $100 \mathrm{M}$ website views per year

At BMC, research is always in progress.

Learn more biomedcentral.com/submissions 